Chirurgia (2021) 116: 643-644

No. 6, November - December

Copyright@ Celsius

http://dx.doi.org/10.21614/chirurgia.116.6.643

\title{
Emergency and Trauma Surgery
}

\section{Valeriu Surlin*}

$1^{\text {st }}$ Clinic of Surgery, Clincal County Emergency Hospital of Craiova, University of Medicine and Pharmacy of Craiova, Romania President of the Romanian Society of Emergency Surgery and Trauma

${ }^{*}$ Corresponding author: Professor Valeriu Surlin $1^{\text {st }}$ Clinic of Surgery Clincal County Emergency Hospital of Craiova, University of Medicine and Pharmacy of Craiova, Romania E-mail:vsurlin@gmail.com
Received: 15.11 .2021 Accepted: 17.12 .2021
According to the UEMS (Union Europeene des Medicins Specialises) Section of surgery \& Board of Surgery, "Emergency Surgery" can be defined "as surgery that is required to deal with an acute threat to life, organ, limb or tissue caused by external trauma, acute disease process, acute exacerbation of a chronic disease process, or complication of a surgical or other interventional procedure". Performance of emergency surgery require complex and varied skills and abilities to achieve procedures from different fields of surgery: abdominal, urologic, thoracic, vascular, soft tissue, skeletal) within an interval of 24 hours (1).

In U.S., since 2008, "Acute Care Surgery" concept was introduced, and nowadays is an evolving specialty with three essential components- trauma, critical care and emergency surgery (2).

In UK there is an increasing subspecialisation within general surgery over the last ten years. More recently, there has been an increase in focus on emergency general surgery $(3,4)$.

This may not come as a surprise given the fact that trafic crashes kill 1.2 million people annually around the world (3242 people/day) and $90 \%$ are in middle and low income countries. In US trauma is the leading cause of death in persons up to 40 years.

Optimal care for emergency surgical patients is one of the major challenges for every healthcare system worldwide. An emergency surgery mai intervene during the daily schedule of elective interventions and create pressure on both the organisation and costs (5).

Since it's birth, in 2007, the Romanian Society for Emergency Surgery and Trauma was involved in supporting the development 
of practice in emergency surgery in Romania by many actions: each year, during biannual National Congres and National Conference of the Romanian Society of Surgery 2 sessions were dedicated to emergency surgery, with invited foreign speakers; oragnisation of European Congres of Emergency and Trauma Surgery in 2017 in Bucharest, 1 tematic issue of Chirurgia Journal dedicated to surgery of the cirrhotic patients.

This tematic isssue includes varia subjects from emergency surgery in valuable articles. The management of open abdomen management are depicted by Anastasiu et al, in a review summarizing definition, classification, indications, methods of temporary abdominal closure and fascial closure, and enterocutanous fistula. Turculet et al, perfomed a review of the litterature to describe the main advantages and disadvantages of the trauma systems in Europe and to present the last concepts regarding the management of the polytrauma patients and the newest sets of measures to prevent car crashes in European Union.

A rare case of small bowel hemangioma with hemoperitoneum mimicking trauma is described by Iordache et al, with a review of the litterature. The series of reviews ends with an interesting article for daily practice in emergency hospitals about the diagnostic and therapeutic peculiarities in abdominal trauma associated with spinal cord injurie by Grigorean et al.

Abdominal trauma is addressed in 7 original papers. The definitive surgery for liver trauma in tertiary HPB center, the non- operative treatment of abdominal trauma involving liver and spleen, the timing of splenic interventional radiology, the management of colon trauma at a level II trauma, challenges raised by the retroperitoneal hematoma in abdominal trauma, predicition of evolution of patients with abdominal trauma using the usual biological parameters, and clinico-pathological correlations in the acute surgical abdomen in the pre and post COVID-19 pandemic period are presented, analysed and discussed in papers coming from specialized surgical units from Fundeni Clinical Institute, Emergency Clinical Hospital Bucharest, Emergency University Hospital of Bucharest, „Bagdasar-Arseni” Clinical Emergency Hospital, "St. Pantelimon" Clinical Emergency Hospital, Clinical County Emergency Hospitals of Craiova and Tg-Mureş.

The surgical technique of intraomental splenic implant and an attempt of reassessement is presented in a paper by Beuran et al.

We hope that this tematic issue will be an interesting and very useful lecture for our readers and bring useful informations for those involved in emergency surgery.

\section{References}

1. (uemssurg.org https://uemssurg.org/divisions/emergency-surgery/accessed 27.12.2021)

2. https://www.aast.org/acute-care-surgery-overview accessesd 27.12.2021

3. RCSEng. The higher risk surgical patient; towards improved care for a forgotten group. England: Royal College of Surgeons; 2011. http://www.rcseng.ac.uk.

4. RCSEng. Emergency surgery: standards for unscheduled care. England: Royal College of Surgeons; 2011. http://www.rcseng.ac.uk.

5. Coccolini F, Kluger Y, Ansaloni L, Moore EE, Coimbra R, Fraga GP, et al. WSES worldwide emergency general surgery formation and evaluation project. World J Emerg Surg. 2018;13:13. 